\title{
8. Parallelism and Poetics in Tindi Narratives Sung in the Ipili Language
}

\author{
Terrance Borchard and Philip Gibbs
}

\section{Introduction}

The Ipili people of Enga Province, Papua New Guinea, have traditional tales, called tindi, which may be told either in ordinary spoken style or as long poetic chanted tales. This chapter focuses on the role that is played by parallelism, which manifests itself in the ordered interplay of repetition and variation in the linguistic and poetic form of the sung versions. Before discussing tindi we will first provide some background details concerning the region. ${ }^{1}$

Ipili is the name of the ethnic group living in the Porgera and Paiela valleys, and is also the name of the language that they speak. As is often found to be the case in Papua New Guinea, the name by which they are known was not coined by the Ipili themselves, but others from outside the region, in this case the Huli to the south. The name they coined, Ibili, ${ }^{2}$ means 'salt-people' in Huli, the Ipili region being known to them as a source for salt. To the people themselves, Ipili refers only to the Porgera Valley. Paiela refers to a different valley on the other side of a high mountain range. The name "Porgera" comes from the Ipili name for the biggest river in the Porgera valley, which flows into the Lagaipa River. The Ipili called it the Poketa River, but the government officers distorted the pronunciation to "Porgera," and identified the valley on the basis of the biggest river flowing out of it. The origin of the name "Paiela" is unknown.

According to the 2000 government census, the Ipili language is spoken by approximately 26,000 people. There are minimal dialectal differences in the forms of Ipili language spoken in those two areas; for example, the second person plural pronoun in Porgera is yakama, but in Paiela, most people say yakamba.

Situated at high altitude near the western end of Enga Province, the Porgera and Paiela Valleys drain into the Lagaip River. It joins the Strickland and eventually the Fly River, which flows into the Gulf of Papua. To the north, in lower altitude

\footnotetext{
1 Although this chapter is a joint effort between the two authors, the introduction and conclusion are mainly by Gibbs. The other sections, including the entire discussion of parallelism, are by Borchard, to whom all instances of the pronoun "I" there refer. The texts considered below are from transcriptions made by Gibbs and Frances Ingemann.

2 The letter $b$ in Huli orthography is equivalent to the letter $p$ in Ipili orthography since both represent an unaspirated, voiceless, bilabial stop; therefore, this word is pronounced the same in both languages.
} 
areas of the Lagaip extending over to the Sepik headwaters, live the semi-nomadic Hewa people, who are culturally very different from the Ipili. The plots of many Ipili chanted tales include depictions of at least some interaction with Hewa, and some Hewa people have intermarried with Ipili people in the border areas, but the Hewa language is related to other languages in the East Sepik Province. It is, therefore, almost entirely different from the Ipili language which, in terms of the latest classification by Ross (2005) and Pawley (2005), belongs to the Engan subgroup of the Trans New Guinea family - a large group of Highlands languages that also includes Enga and Huli. ${ }^{3}$

Over the ranges to the east live the Taiyaro Enga, and to the southeast, the Kandep Enga of the Wake (Wage) valley. To the south, several days walk over rough limestone country, live the Huli of the Tari basin. To the west, also several days walk away, live the Duna people of Lake Kopiago. The Enga and Huli are large, powerful groups and a major force in the region, economically, culturally, and to some extent linguistically. The Duna language belongs to a different subgroup within the Trans New Guinea family, and does not share much vocabulary with Ipili except for a few words borrowed by people who live in the border area between the two language groups. Ipili shares much more vocabulary with Huli and Enga than it does with either Duna or Hewa, due not only to its closer genetic relatedness to them, but to continuing, extensive social interaction, including intermarriage between Ipili and Enga people, especially those who live east of the Ipili area. Many Ipili trace their ancestry back to Enga or Huli origins.

Human contact through visits by hunters in Porgera extends back at least 11,000 years (Jackson and Banks 2002:9). Human habitation goes back more than ten generations. Ipili have been part of trade and ritual networks shared with their neighbours. Salt and axes were traded to the south for tree oil, ochre, and black palm bows. Ritual networks in the Ipili area were linked to the Huli dindi gamu cult and the Enga kepele ritual. These networks were reinforced by marriage, ensuring an extended network of relatives who could also provide security in time of famine or feud.

First contact with the modern world may have occurred in 1934 when the Fox brothers travelled down the Lagaip River, crossed the Porgera River, continuing through Paiela to the Strickland Gorge area. The next European in the area was Jim Taylor, who passed through Porgera in 1938 during the Hagen-Sepik Patrol. In 1939 John Black crossed the Porgera River again and found gold. That discovery signalled dramatic changes for Porgera. In 1945 an Australian New Guinea administrative unit visited while searching for lost airmen. After the war a number of expatriate prospectors came in search of gold.

3 For further details, see chapter 1. 
Mission contact started officially with de-restriction of the area in 1962. Four Christian churches came initially and now at least another eight churches are established. Scholars coming to research and write have included Glenn Banks, Aletta Biersack, Alex Golub, Jerry Jacka, Frances Ingemann, and the authors of this chapter.

In a short time Porgera was transformed from a traditional Highlands society living by gardening, hunting, and gathering into the site of one of the largest gold mines in the world. As Golub notes, in less than thirty years the owners of the land on which the mine operates went from their first exposure to money to receiving roughly four million kina (over a million US\$) a year in royalties alone (Golub 2001:26).

Today, despite an access road and the nearby Mt. Kare gold deposits, Paiela remains a relatively isolated valley. Porgera, however, is changing very fast with the presence of the gold mine administered by Porgera Joint Venture, of which Barrick Gold is the majority shareholder. The mine employs over two thousand workers, and there are many other contractors and associated industries at the site. The 2000 Census records 11,084 people in Paiela and 22,809 people in Porgera. The Paiela population is increasing at a moderate rate, but the Porgera population is growing at a very high rate of about $8 \%$ per annum, mostly due to immigration from other parts of Enga and the Southern Highlands. Now at Paiam in the Porgera Valley, there is a well-equipped hospital, several primary schools, secondary and international schools, a university centre, postal and telephone services, electricity, radio, TV, water and sewage plants, a bakery, car sales, a motel, and guest houses. Not everyone has access to resources to benefit from such facilities, however Porgera today has the atmosphere of an urban centre.

Differences of custom follow a gradation from the east, which is influenced by Enga, to the south, which is influenced by Huli. Ipili people in Porgera make a distinction between the wakiame speakers, who are influenced by their Enga neighbours, and the tumbiame speakers, who some Porgerans say speak "pure" Ipili. Such a claim might be contested by Paiela people who are more influenced by the Huli. Despite these outside influences, Ipili follow cultural patterns that are distinctively their own-language being one of these.

Ipili have formed their lives from the sources offered by the Papua New Guinea Highlands context. Society is strongly stratified along gender lines, and young men used to go for long periods to the forest to participate in initiation rites. Marriages are formed so as to strengthen or extend alliances, and the exchange of pigs formed the basis of the traditional economy. Today, cultural traditions are changing rapidly as young people attending school choose their own marriage partners and use money both in exchange and to buy the necessities of life. 
The Ipili do not have sharply delineated clans, such as in the patrilineal clan society of the neighbouring Enga. Rather, Ipili tend to organise themselves into kindreds - all the people who can claim to be related because they share a common ancestor. In Ipili society one can claim membership in any kindred that one's grandparents were members of. As a result each person has potentially eight cognatic stocks of which they can be a member. Membership of multiple groups is desired as providing a larger security circle, but can have drawbacks today in overcrowding and the risks of illegal mining.

Traditionally sweet potato was the staple food of the Ipili, supplemented by taro. Hunting and gathering was also important, particularly during the season for harvesting pandanus nuts. Pigs were valued as a source of food, but even more for exchange. Today, as the population increases with consequent pressure on the remaining land, many Porgerans rely more on store goods, such as rice and tinned fish.

These life themes - tribal origins, initiation rites, marriage and gender relations, hunting, and gardening - are recurring elements in the chanted tales called tindi.

The following section provides background details about some aspects of the grammar of Ipili which especially are relevant for the later discussion of parallelism in Ipili chanted tales.

\section{Aspects of the grammar of Ipili}

Ipili is what linguists refer to as an SOV language. The "S" in this formula indicates the normal position of the subject in a sentence or clause, " $\mathrm{O}$ " the normal position of the object, and "V" the normal position of the verb. By contrast, English can be referred to as an SVO language because the main verb in a clause is normally preceded by the subject and followed by the object.

For example, for "John hit Peter," an Ipili speaker would say Joneto Pita pelea, which puts the subject first, the object next, and the verb at the end of the clause, whereas in English the order is subject-verb-object.

Nouns and other parts of speech are often in the final position in lines of English poetry and songs that rhyme with each other. However, as a result of the fact that Ipili is an SOV language, a verb is almost always in the final position in the lines that are parallel in an Ipili chanted tale. This makes Ipili verbs so important for creating parallelism in Ipili chanted tales that well over $90 \%$ of the examples of

4 I am using the term "clause" in the linguist's sense to refer to a syntactic construction which has a subject and a verb if it is an intransitive clause, and also an object if it is a transitive clause. A sentence is a potentially more complex unit, which may consist of either a single clause or a series of clauses. 
parallelism in this chapter are a result of having the same or very similar verb forms or verbal suffixes at the end of two or more lines. There are more than a hundred different forms of each Ipili verb that can be used to create a variety of very natural forms of parallelism in Ipili chanted tales. In the rest of this chapter, many examples are presented of the different ways the various forms of the Ipili verb can be used to create parallelism.

Ipili verbs are conjugated to show not only the remote past, present, and future tenses, but also the imperfect and perfect aspects, as well as many other finer shades of meaning too numerous to discuss in this chapter. The imperfect aspect is used not only to refer to very recent events, but also to refer to a process which has begun, but is not yet finished. By way of contrast, the perfect aspect is used in situations where an event has been completed. This distinction between actions that have been completed and actions that have not is made not only in sentencefinal Ipili verb forms, but also in other forms of the verb that will be discussed in connection with some of the specific examples in the rest of this chapter.

In Ipili sentence-final verb forms, there is a natural interplay between tense and aspect, since events which began recently are less likely to be completed than events which began farther in the past. As a result of this interplay between tense and aspect, the chanter of a tale may chose to use the imperfect aspect rather than the present tense to announce that he is starting to chant a tale because he wants to focus on the fact that he is beginning a process that will not be completed for a while. In another place in the same chanted tale, the chanter of tales may choose to use the perfect aspect to refer to something that he said or to something the listeners heard about only minutes ago, even though those same verb forms are often used to refer to events that happened at least a day ago.

\section{Parallelism: Some general considerations}

The poet Gerard Hopkins focused very clearly on the importance of parallelism as an artistic feature when he wrote in 1866 that "The artificial part of poetry ... reduces itself to the principle of parallelism" (Hopkins 1959:267). This assertion about parallelism influenced Roman Jakobson who studied it from a linguistic perspective for more than fifty years and stated that "on every level of language the essence of poetic artifice consists of recurrent returns" (Jakobson 1966:399). Parallelism is a poetic feature shared by several genres, including poetry and songs in most cultures in the world, and shared also in the tales chanted in the Highlands of Papua New Guinea, as will be evident not only from this chapter, but from several of the others in the volume, especially chapters $1,4,6,10$, and 11 . 
In my discussion of parallelism in tales chanted in the Ipili language, I have grouped examples of parallelism together on the basis of four main types of parallelism: $(a)$ the creation of parallelism by substituting terms within a frame; (b) the use of extra non-semantic syllables of the kind known as "vocables," as discussed in chapter 1; $(c)$ the creation of parallelism by using medial-verb forms; $(d)$ the creation of parallelism by using sentence-final verb forms. Textual examples illustrate all of these types. The terms used to distinguish these four groups will be explained in the individual sections where the examples are given.

Lomas (pers. comm.) notes that these four main types and eight subtypes of parallelism can be found not only in chanted tales, but also in other spoken and sung genres of Huli. He points out that these types of parallelism are consistent with the notions of Hopkins (1959) and others, and that both Hopkins and Hunter (1999:46-61) would have predicted that these kinds of parallelism would be used in this wider range of contexts. I have not systematically studied parallelism in other genres of Ipili, but it is certainly a prominent feature of the traditional songs sung in the Ipili language. Examples of these kinds of parallelism in Ipili songs can be found in a paper by Frances Ingemann (1968), in which she describes the traditional song form, which uses specialized vocabulary and lines that are similar to the repetitive lines in chanted tales.

Parallelism has been studied and discussed by many scholars, but it has taken centuries to make clear distinctions between the various aspects of that term. Lowth defined parallelism very broadly in 1778 when he distinguished between parallel lines and parallel terms by saying, "When a proposition is delivered, and a second is subjoined to it, or drawn under it, equivalent, or contrasted in sense, or similar to it in form of grammatical construction, these I call parallel lines, and the words or phrases answering one to another, in corresponding lines, parallel terms" (Lowth 1843:ix). It seems clear from Lowth's use of the term "equivalent" that he would consider lines that are identical as being parallel.

However, in discussing a chanted tale from the $\mathrm{Ku}$ Waru region of the Western Highlands Province of Papua New Guinea, Rumsey notes that "the language is not merely repetitive, it is systematically repetitive, making frequent use of parallelism, whereby each instance of partial repetition establishes a framework within which there is significant contrast at equivalent positions from line to line" (Rumsey 2005:49). This recognition of significant contrast as an aspect of lines that are parallel to each other indicates that lines which are identical should not be considered parallel lines. It is better to just refer to them as being identical, and to refer to lines that include both repetition and contrast as being parallel .

Fox (1977) affirms the importance of contrast as a feature of parallelism when he distinguishes between two different aspects of parallelism by saying that one aspect focuses on parallelism as "an extension of the binary principle of opposition to the phonemic, syntactic, and semantic levels of expression" (ibid.:60). He 
goes on to say that the other aspect focuses on "the specific manifestations of this binary principle as a strict, consistent, and pervasive means of composition in the traditional oral poetry of a wide variety of peoples of the world" (ibid.).

Rumsey (2001:207) points out that in the chanted tale that he is discussing, "partial repetition establishes syntagmatic frames within which there is paradigmatic contrast at equivalent positions from line to line." Contrast between parallel terms at equivalent positions is a feature of parallelism that distinguishes lines that are parallel from those that are not. Fox (1977:75) notes that parallelism can be analysed in terms of whether parallel terms within the verse frame occur in the initial, intermediate, or final position. The examples of parallelism in Ipili chanted tales which I will discuss all have contrast between parallel terms in either the initial or intermediate position. The terms in the final position are either identical, or at least very similar in some way, and therefore function as at least part of the frame within which the parallel terms are contrasted.

\section{Parallelism in Ipili chanted tales}

An Ipili chanted tale is referred to as a tindi. Magical things can happen in a tindi. For example, in the tindi named "Kau nala tapeyo," the main character changes from being a small boy to being a big man as a result of eating special sweet potatoes or taro that were given to him by a woman. Then later on he magically becomes a boy again after he eats more of that food. He goes through that magical cycle of change repeatedly. The term tindi contrasts with the term temane which refers to stories about events that have happened in everyday life. Parallelism in a temane would be coincidental, rather than intentional as it is in a tindi. The term tomo refers to traditional Ipili songs that also have extensive parallelism, but such songs are beyond the scope of this chapter.

The examples used here to illustrate parallelism are taken from four different chanted tales. All four stories focus on the same main character, who eats lizards instead of pig meat, although the degree of emphasis on that aspect of his character varies. His older brother is referred to as Kima and Kimape in three of the tales, and that brother is also said to be from Kengone in three of the tales. Many of the details in each chanted tale are different, but there are many similarities also. The main character goes on at least one long journey during which he meets a young woman. He interacts with the Hewa people and pays bride price to them at some point in each story. After he and the young woman experience many things together during their journey, they finally climb a high mountain until they reach the clouds and enter the sky world.

I have named each of the chanted tales based on the way the main character is referred to in that chanted tale. "Kau nalane akali" in line 57 of that chanted tale 
(Yandapake 1964b) means "The man who customarily eats lizards." "Kau nala akali" in line 1022 of that chanted tale (Yandapake 1964a) means "The man who just ate a lizard." "Kau nala tapeyo," which is used many places in that chanted tale (Kale 1974), could mean "The lizard who just ate a lizard." "Kau tali tapeyo," which is used many places in that chanted tale (Kaneanda 1965), could be a subtle play on words to refer to the fact that he offered to share his lizards in that story. His alternate name in that tale, "Kau Tali tane," could mean that he was an inhabitant of the Tari area, which isn't too far from the Ipili area.

An Ipili chanted tale is characterized by a high degree of parallelism of various kinds within some of the paragraphs. Some of the parallelism is created in a very natural way, based on the fact that Ipili is an SOV language that normally places the verbs at the end of each line, as discussed above. The result is that having similar verb forms at the end of two lines can create parallelism. However, some of the parallelism is produced in a very creative way by structuring some of the paragraphs in ways that are not typical in other genres of discourse in the Ipili language. I now turn to a discussion of each of the four types of parallelism that I have distinguished above.

\section{Parallelism created by substituting one or more terms}

Some successive lines in Ipili chanted tales are identical. But identical repetition does not seem to be valued as highly as parallelism, which requires more rhetorical skill and creates the impression that the story is moving along, even though it is only by the parallel terms that are changing within the framework established by partial repetition.

Two or more lines in a paragraph may be identical except for one word that may be changed slightly by adding one additional syllable at the beginning, in the middle, or at the end of one of the words in the second line. The two lines in text 1 are exactly the same except that the word Yongopena in line 22 contains the additional syllable -ngo-, which is not in the word Yopena in line 21.

Those two words are parallel terms in the intermediate position set within a framework formed by Nena ipa in the initial position and yoko tepa ya-o in the final position in both lines.

\section{Text 1. Example from "Kau nala tapeyo."}

21. Nena ipa Yopena yoko tepa ya-o.

22. Nena ipa Yongopena yoko tepa ya-o.

Other pairs of lines are identical except for one or two words in the second line that have been substituted for one or two words in the first line. The words 
may be similar in meaning or refer to the same kind of entity, but they may be completely different in form. The two lines in text 2 are exactly the same except that the words yuu pokoli in the intermediate position in line 1181 have been substituted for the word tunduni in the intermediate position in line 1180. The words refer to similar kinds of entities, but are not similar in form like the words Yopena and Yongopena in lines 21 and 22 in text 1.

The substitution of the words yuu pokoli for the word tunduni is an example of "semantic" parallelism, in which parallel terms are semantically related, but may not have any formal similarity to each other. The repetition of the other words in the initial and the final positions of those two lines serves as the framework within which that contrast is used to create parallelism.

\section{Text 2. Example from "Kau nala tapeyo."}

1180. Iyu tunduni mindi yane okona mee He climbed way up on a mountain that was there. keyea-ko.

1181. Iyu yuu pokoli mindi yane okona He climbed way up on a ridge that was there. mee keyea-ko.

The word or words that are different may be the name of a place, or a kind of plant or animal or bird. Often the information given could have been given more concisely by simply listing these items within a single clause. That is what is normally done in some genres of Ipili when the focus is on giving information as concisely as possible, but in chanted tales, each item is put into a separate line in order to create more extensive parallelism, thereby enhancing the aesthetic appeal of the chanted tale for the listeners and demonstrating the poetic skill of the chanter.

Sometimes the pattern of substitution becomes more complex. In text 3 , the word in the initial position in both lines is identical, so it serves as part of the framework for the contrasting parallel terms created by substituting the place name Anduni in line 1126 for the place name Kiyuni in line 1125. The next word in both lines is identical, so it is also part of the repetitive frame. It is followed by another contrasting pair of parallel terms created by substituting the name Kimape in line 1126 for the name Kima in line 1125, even though they refer to the same individual. This is another example of the addition of one syllable making the second line different from the first. In both lines, the next four words following the names Kima and Kimape are also identical except for the addition of the vocable $-o$ at the end of line 1126.

\section{Text 3. Example from "Kau nala tapeyo."}

1125. Yuu Kiyuni akali Kima uli atu epeyo ote lea.

1126. Yuu Anduni akali Kimape uli atu epeyo ote lea-o.
"I am coming here with the Kiyuni place man Kima," she said.

"I am coming here with the Anduni place man Kimape," she said. 
In other examples of parallelism, the parallel terms occur in the initial position. The pairs of lines are identical except for one whole word which is added somewhere in the second line. In text 4 , the two lines are identical except that the word eka 'bird' has been added at the beginning of line 269 .

\section{Text 4. Example from "Kau nala tapeyo."}

268. Ambi okone peyokale-ko, alo lea.

269. Eka ambi okone peyokale-ko, alo lea.
"I want to kill that one over there," he called out.

"I want to kill that bird over there," he called out.

It may seem strange to consider the absence of a term in one line as one of the parallel terms in a pair of parallel terms, but it does create a contrast between lines 268 and 269 within a framework of repetition which is a basic component of lines that are parallel. It may also be more difficult to think of the word and its absent counterpart as being within a "frame" because they occur in the initial position, so all of the words that are identical are on one side. However, it has already been stated that the parallel terms in lines that are parallel can occur in the initial position.

\section{Parallelism enhanced by adding non-semantic syllables or words}

Chanters sometimes add a syllable to the end of the last word in a line, even though the addition of that syllable does not change the meaning of the line. Such syllables are sometimes referred to as non-semantic syllables. A whole word may be added at the end of a line even though it doesn't change the meaning of that line. Since they don't change the meaning of the line, it seems that these syllables or words may be added primarily for the aesthetic effect they produce in an Ipili chanted tale.

\section{Parallelism enhanced by adding a single syllable at the end of lines}

An additional syllable -o is sometimes added at the end of several lines, even when they would already be parallel without adding that syllable. The three lines in text 5 would not be parallel without adding the word lea which means 'she said'. However, repeating that word in the final position in all three lines creates a frame within which all of the other words that precede it in each line become parallel terms in a broad sense since those words in each line contrast with the words in the same position in the other two lines.

Therefore, all three lines would already be parallel without adding the vocable $-o$. Vocables are not normally added in several successive lines in other genres of Ipili discourse, and their addition does not affect the meaning of the chanted 
tale in any way. They are apparently added only to enhance the aesthetic appeal of this genre by allowing the chanter to hold a given musical note for a more extended period of time than would be natural without it.

\section{Text 5. Example from "Kau nala tapeyo."}

1375. Andipa langukale. Ipu napele okonde lea-o.

1376. Yia kee puyale, wanda tewa pii lalawa aya napiyainipe lea-o.

1377. Pee, mindimane wua leya lo layango lini lo atelepe lea-o.
"Now I want to ask you. What about the fact that you are not coming?" she said-o.

"Being about to cut up pig, don't women talk a little?" she said-o.

"Or by saying that someone is saying that, are you slandering (them)?” she said-o.

In text 6, the same vocable - $o$ is used on two different verbs, lea and epea. These verbs have very different meanings: lea means 'he said', whereas epea means 'he came'. Although the verb stems are different, they have the same third person singular remote past suffix -ea. It creates a very natural kind of parallelism when two or more lines end with verbs that have the same suffix, even if the meaning of the verbs is different.

It might seem to be stretching the definition of parallelism to say that having the suffix -ea in the final position in both lines is enough repetition to serve as a frame for the contrast between all of the rest of the words in those two lines which then function as the parallel terms in this example. However, English speakers immediately recognize the parallelism between lines of poetry and songs in which only the last word in one line rhymes with the last word in another line.

The parallelism is further enhanced by the addition of the vocable - $o$ at the end of many lines in chanted tales in Ipili. This is similar to what is done in chanted tales in many other Papua New Guinea Highlands languages (as discussed by Niles and Rumsey in chapter 1). To create an aesthetic affect, the chanter may continue the -o sound at the end of a line much longer than other syllables would be continued in everyday speech. This expands the final-position repetitive frame from just the verbal suffix -ea to a slightly larger frame -ea-o. Continuing the sound of the last syllable also helps to draw attention away from the fact that the stem of the verbs at the end of the two lines is different.

\section{Text 6. Example from "Kau nala tapeyo."}

466. Iyu andaka pekaiyu loto, lama epea- Arriving at the house up above, she came sayingo. o.

467. Iyu ulia pote yangalo oko patipakale ote lea-o.

"Let's take the pote sweet potatoes I just cooked out of the ground oven up above," she said.

The syllable - $t a$ is sometimes added at the end of two or more lines in a chanted tale even in contexts where the lines are already identical. 
The suffix -angi at the end of lines 5 and 6 in text 7 identifies them as dependent temporal clauses. I have never heard the syllable - $t a$ used as an addition to the suffix -angi in normal everyday speech. Therefore, it seems that it is added to the ends of lines in Ipili chanted tales primarily for aesthetic effect. It may be that these can only be fully appreciated by someone whose mother tongue is Ipili. In ordinary every day speech, lines 5 and 6 would be coalesced into one clause by mentioning the earth and the rivers in the same clause, but they are mentioned in two separate clauses to create parallelism in this chanted tale.

\section{Text 7. Example from "Kau nala tapeyo."}

5. Yuu uli oko yoale, ungi mindi leaangi-ta,

6. ipa uli tupa yoale, ungi mindi leaangi-ta,

7. akali ote api yale lo makande pua,

8. Iwanaya Auwala yale mindi atalane lea.
When there was a beginning for this earth to exist,

when there was a beginning for the rivers to exist,

comparing, saying, "really like which man?"

a small boy like Auwala customarily existed, he said.

The parallelism in a chanted tale is sometimes enhanced by the addition of the suffix $-k o$ on the verbs at the end of two or more lines. This suffix often indicates that the previous sentence is the ground or basis for a question, statement, or command that follows that clause, but it does not seem to have that meaning in this context. Ending two or more lines with the suffix - $k o$ creates parallelism where it would not otherwise occur because the verbs that precede it are different.

In text 8 , lines 159 and 160 are already parallel without adding the suffix $-k o$, because the words ipa and dundu pea in both lines create a framework of repetition within which the words Lai and Lakai are parallel terms, along with the word Nenanga in line 159 and its absence in line 160 which creates another pair of contrasting terms within a framework. Adding the suffix $-k o$ to line 161 enhances the parallelism with lines 159 and 160 by slightly expanding the repetitive framework in those two lines. On another level, adding that suffix also makes line 161 parallel to lines, 159 and 160 even though the content of line 161 and the verb to which that suffix is attached is different from the content and verb in lines 159 and 160.

\section{Text 8. Example from "Kau nala tapeyo."}

159. Nenanga ipa Lai dundu pea-ko. He went along the Lai River.

160. Ipa Lakai dundu pea-ko. He went along the Lagaip River.

161. Pulu, molo Ewa anda pekayu lea-ko. Having gone, he arrived at the Hewa house.

Text 9 also includes the suffix $-k o$. The parallelism in this example is very interesting because of its complexity and the way it is structured. Lines 534 and 536 are identical, rather than parallel. However, lines 533 and 534 taken together 
as a larger unit are parallel with lines 535 and 536 taken together as a larger unit, because lines 534 and 536 create a repetitive framework within which lines 533 and 535 function as parallel terms because they are not identical and therefore contrast with each other. All of line 535 functions as a substitution for line 533 to create the interplay of repetition and variation with these two larger units that is characteristic of parallelism.

In addition to the parallelism at that higher level, line 535 is also parallel to line 533 even though it does not immediately follow it. The repetition of the words ipa and tupa po atalawane-ko in both lines creates a framework within which the words Tulini and Wakepe in the initial position and Wau and pete peangolo in the medial position function as two pairs of parallel terms.

\section{Text 9. Example from "Kau nala tapeyo."}

533. Tulini ipa Wau tupa po atalawaneko.

534. Yawa. Yawape lea.

535. Wakepe ipa pete peangolo tupa po atalawane-ko.

536. Yawa. Yawape lea.
"Going to the Wau River at Tulini, I customarily stay there," he said.

"Cook (it) in a ground oven. Please cook (it) in a ground oven," he said.

"Going to the Wagi water pools, also I customarily stay (there).

Cook (it) in a ground oven. Please cook (it) in a ground oven," he said.

Both lines 534 and 536 could also theoretically be subdivided into two parallel lines with only Yawa on the first line. That word can function as a complete sentence by itself, since it is the second person singular imperative form of the verb, indicating that the command should be obeyed immediately. The second line would then say Yawape lea, which would introduce variation by adding the syllable -pe to create the polite form of the second person singular imperative. This form gives the person to whom the command is given more discretion as to when the command will be obeyed.

Even though it would theoretically be possible to subdivide lines 534 and 536 in this way, it seems unlikely that the chanter intended his listeners to think of the word Yawa as a complete line by itself, since no line in any Ipili chanted tale I have ever seen has been that short. He could have chosen to make this line long enough by adding one of the more complex speech orienters that I discuss later in this chapter, and then using that same complex speech orienter at the end of the second line. Instead of doing that, he used lea which is the shortest possible speech orienter, so it seems clear that he intended for his listeners to consider both forms of the imperative to be part of the same line. 


\section{Parallelism enhanced by adding a whole word at the end of a line}

Sometimes a whole word is added at the end of one or more lines of a chanted tale. In text 10, the Ipili word andoko is added to the end of lines 82 through 86 and within line 87, but Ingemann (1964:n. 2) reports that the Ipili speaker who helped her translate this chanted tale said the word andoko has no meaning in this context. In other contexts it sometimes means 'which one' or 'where' or seems to be intended to elicit agreement from the person to whom the speaker is speaking, but none of those meanings seem to fit here. Lines 82 through 86 certainly would not be parallel if the word andoko had not been added at the end of each line, but adding that word makes them all parallel.

\section{Text 10. Example from "Kau nala akali."}

82. Amene, nena Kolali ipa tindininga late lauwa andoko.

83. Lakae ipa dundu puwa andoko.

84. Iyu Uyu mane late lauwa andoko.

85. Luyupe mane late lauwa andoko.

86. Namba amene, napele yala andala baa taimane peke lalo andoko.
"Brother, I went in the middle of the Kolali River.

I went along the Lakae River.

I went up to the head waters of the Uyu River.

I went up to the headwaters of the Luyupe River.

Seeing that my brother was not attacked, I have returned quickly.

Having said, 'I am coming,' he told him," he said.

The third person singular remote past verb form lea in line 87 of this example means 'he said'. This makes it seems like the chanter is telling the tale as though he is quoting or repeating what someone else told him, since the previous word lamaiyane serves at the speech orienter indicating what the younger brother told the older brother.

Based on Alan Rumsey's extensive study of Ku Waru chanted tales, he says, "There are other commonly used metanarrational formulas that seem to take as their implicit grammatical subject the tale itself, as if it were an active force making itself manifest in the inner eye and ear of the performer and through him/ her to the audience" (Rumsey 2001:208). However, in this Ipili example, it seems to me that the chanter would have used the immediate past tense of the Ipili verb that means 'say' instead of the remote past tense if he meant that the chanted tale itself is the implicit subject that is ultimately telling the tale being given outward expression by the chanter.

My view is based on the fact that the chanter did use the first person singular immediate past tense verb form lalo when he announced that he was ready to begin the chanted tale. I would have expected him to use the present tense first person verb form leyo to announce this, just as people often use that present tense verb form to announce the fact that they are about to say something in other contexts, such as meetings in which many other people might also want to have a chance to speak. 
However, what people say as part of a discussion in a meeting is usually quite brief, whereas some chanted tales are very long and take a long time to tell, so telling one can be thought of as a process that is not completed until the tale is finished. When a tale is finished, the chanter announces that fact by saying koyo, which means 'finished', whereas a man who uses the present tense to announce the fact that he is about to say something at a meeting does not announce the completion of what he is saying by using that word. He simply stops talking. So it seems to me that the chanter's choice of the remote past tense of that verb indicates that the implicit subject of the verb "said" in this context is some other chanter who told that same tale at some indefinite point of time in the remote past.

\section{Parallelism created by using medial verb forms}

As discussed above, in Ipili the verb normally comes at the end of the clause in which it occurs. There are two different sets of verb forms. One set is referred to as "medial" because they are never used at the end of the final clause in a sentence. The other set, which occurs in that position, is accordingly referred to as "final" verb forms.

The primary function of the medial forms is to specify the relationship between the clause of which the verb is a part and the following clause. However, both medial and final verb forms are often used by chanters of Ipili chanted tales to create parallelism through repetition of either the same verb or the same verb suffix at the end of more than one line in succession. In this section I will show how Ipili chanters create parallelism by repetition of the same medial verb form at the end of two or more lines. In a subsequent section, I will show how they do so by repetition of the same final verb form at the end of two or more lines.

Some medial verb forms indicate that the subject of the next clause is the same as the subject of the one in which they occur, while others indicate that it is different. Other forms do neither. The role of these three kinds of verbs in the creation of parallelism is discussed in the following three sections.

\section{Parallelism created by using same-subject medial verb forms}

There are some medial verb forms in Ipili which indicate that the subject of the following clause is the same as the subject of the clause which ends with one of these medial verb forms. These medial verb forms are not inflected, so they do not give any information about the time the event occurred or the person or number of the subjects who participated in it. The number of the subject (singular, dual, or plural) of a medial verb may be indicated in the medial verb itself, but the rest of the information about the event is given in the suffix on a conjugated verb form at the end of some other clause that occurs later in the sentence. 
In text 11 , the content of line 828 is parallel with the content of line 827 because the words wana tupa in the initial position and the word pituto in the final position provide a frame of repetition within which the words iyu yangi Kuma nenenga is a group of terms in line 827 which is parallel to the words Kulame wangeanenga in line 828 . Likewise, the content of lines 830 is parallel with the content of line 829 because the words titikini eka in the initial position and yaka-yaka pituto in the final position in both lines provide a frame of repetition within which the contrasting words tenda and tendekene function as parallel terms.

\section{Text 11. Example from "Kau tali tapeyo."}

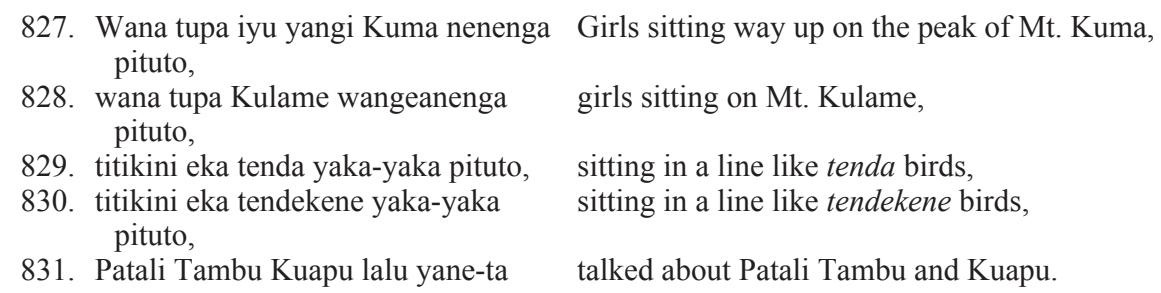

At a higher level of parallelism, lines 827 through 830 all end with the same medial verb form pituto, so all four of these verses are parallel, with the repetition of the medial verb functioning as the frame and all of the words which precede it in each line functioning as groups of parallel terms. This medial verb form is similar to a participle in English and means 'sitting'.

This medial verb form doesn't give any information about the number of the subject or when this event happened, but the third person singular remote past verb form at the end of line 831 retrospectively provides this information. The same subject suffix -to at the end of lines 827 and 828 indicates that the subjects of the following lines 829 through 831 are the same as the subjects of lines 827 and 828. That suffix also indicates that the activity of talking took place simultaneously with the activity of sitting.

In text 12 the repetition of the words lipi ongane in the initial position and the words tupa yata wato in the final position in lines 24 and 25 create a frame within which words kii pipi and kai maukale function as contrasting parallel terms. In this example also, the medial verb suffix -to at the end of lines 24 and 25 doesn't give any information about when those events happened, but the remote past verb form at the end of line 26 provides the information that it was in the remote past. The medial verb suffix at the end of those lines also indicates that the subject who is doing the activity in line 26 is the same as the subject of lines 24 and 25. 


\section{Text 12. Example from "Kau nala tapeyo."}

24. Lipi ongane kii pipi tupa yoko yata wato,

25. lipi ongane kai maukale tupa yoko yata wato,

26. ende pape ima peyalu, yangapia.
Cutting down pipi (trees), putting them up here, cutting down maukale (trees), putting them up here,

having built a stake fence, he burned (the garden area).

The two kinds of trees that are mentioned in text 12 would normally both be mentioned in the same clause in everyday speech, but they are mentioned in separate clauses in this chanted tale to enhance the parallelism within the text. The fact that all of the other words except the names for the trees are the same creates excellent parallelism with lines 24 and 25 both ending with the same medial verb form yata wato, which means 'putting them'.

\section{Parallelism created by using different-subject medial verb forms}

There is a medial verb suffix which indicates what linguists call "switch reference." That is, it indicates that the subject of the following clause is different from the subject of the clause that ends with the suffix -kola. This suffix is not used in two successive clauses very often in everyday speech, but it does create a sense of parallelism when it is used in two successive clauses in a chanted tale given in text 13 - the repetition of the suffix - kola in the final position serves as a frame for the rest of what is said in lines 858 and 859 which function as parallel terms.

\section{Text 13. Example from "Kau nala tapeyo."}

858. Nimba amene-mane pipia-kola,

859. namba peyowa tupa yatakawa pitiwasia, ipupi-kola,

860. peyauwa lea.
"Your brother just did (something) and then, while I was still angry, you came and so,

I hit (you)," she said.

In text 14, the word ote at the end of two or more lines also creates parallelism where it would otherwise not occur. It is often indicates that the line that precedes that word states a critical part of the context or situation in which the events that follow occur. In this example, the young woman would not have met the man if she had not gone to that place.

Lines 284 and 285 would not be parallel at all without the word ote at the end of each line since the verbs are different, but repeating ote in the final position in line 285 creates a frame within which the rest of what is said in both of those lines serves as groups of parallel terms. Ending both clauses with ote indicates that both lines have the same relationship to line 286 . 
Sung Tales from the Papua New Guinea Highlands

\section{Text 14. Example from "Kau tali tapeyo."}

284. Wana ekene kapi molo peka tupa tepa mindi ya ote,

285. aiyako mane nenanga atea molo pu nena lalu, atea ote,

286. Kau Tali Tane yalua andelepa?
That unmarried young woman jumped down to get ferns and then,

she having gone down to get ginger, was there and then,

do you see Kau Tali Tane there?

\section{Parallelism created by using medial verb forms that can have either same or different subjects}

Conditional clauses are created in Ipili by adding the suffix - $n d o$ at the end of the remote past form of the verb at the end of a non-final clause in a sentence. The subject of the clause that follows a clause that ends with this suffix can either be the same or different. Clauses that are marked as being conditional specify the conditions for the consequence that is stated in a following clause, which is usually the last clause in the sentence.

In text 15 , line 815 is identical to line 814 except for the addition of $n a$ in line 815 in the Ipili. $\mathrm{Na}$ is a shortened form of the first person singular personal pronoun namba. This is redundant information because the verb ateyo in both line 814 and 815 has a first person singular present tense suffix. The addition of $n a$ in line 815 contrasts with its absence in line 814 , creating a pair of parallel terms within the framework created by the repetition of the rest of the words in those two lines.

\section{Text 15. Example from "Kau tali tapeyo."}

814. Ateyoko, na-ipulu mindi peendo,

815. na ateyoko na-ipulu mindi peendo,

816. wua piya mala makipu okomane tombo mindi yando,

817. wua piyane andupi okomane lita mindi peando,

818. Kau Tali Tane tingi mialawane, yuku-pene lea.

819. Kau Tali Tapeyo ipulu, mialawane yuku-pene lea.
I am staying, so if you don't come (back), I am staying, so if you don't come (back), if there is a dividing line because of what he just did,

if there is a boundary because of what he customarily does,

I, Kau Tali Tane, crossing over, customarily take fiercely," he said.

I, Kau Tali Tapeyo, having come, customarily take fiercely," he said.

The repetition of wua in the initial position and the suffix -ndo in the final position of line 817 create a repetitive frame that makes it parallel to line 816 . All of the words in the intermediate position in both lines serve as groups of parallels terms. Even though many of the specific words in those two groups of Ipili words are different, the word 'boundary' (lita) in line 817 is very similar in meaning to "dividing line" in line 816. This kind of lexical parallelism further enhances the parallelism of these two lines. 
Even though the suffix -ndo has been added to three different verbs at the end of four lines, it makes them all parallel by creating a repetitive frame for parallel groups of words which say everything else that is said in those lines. All four of these lines state conditions that relate to the consequence stated in line 819 . It would certainly be unusual to have four conditional clauses in one sentence in everyday speech, although several conditional clauses are sometimes strung together in a chain, if many conditions are being stated as leading to the same consequence.

The suffix -nga on a verb at the end of a clause identifies that clause as a locative clause in relationship to a following clause which states what event happened, or what situation existed at that location. In text 16, lines 1347 and 1348 are two locative clauses ending with the suffix -nga which tell where the scrawny pig was tied up. ${ }^{5}$

The locative word ambingane meaning 'over there' in the initial position and the words palu tupa lolo andi leanenga in the final position form the repetitive frame within which the contrastive words one and kiwaki are parallel terms, making these two lines parallel. In everyday speech, there would not normally be two locative clauses in succession in the same Ipili sentence, because the two parallel terms would be included in the same clause. But in this Ipili chanted tale, the parallel terms are put into two separate successive locative lines to create parallelism.

\section{Text 16. Example from "Kau nala tapeyo."}

1347. Ambingane one palu tupa lolo andi leanenga,

1348. ambingane kiwaki palu tupa lolo andi leanenga,

1349. mindiki angu amonga andi leae ya lea.
Over there where the light coloured ones were tied up,

over there where the grey and tan ones were tied up,

there was only one (scrawny pig) tied up way over there, she said.

\section{Parallelism created by using the same sentence-final verb form}

In this section I will give examples to illustrate how chanters of Ipili chanted tales create or enhance parallelism by repetition of the same sentence-final verb form at the end of two or more lines.

5 The suffix -nga itself does not mean 'over there'. 'Over there' is the meaning of the first word in the Ipili. Ipili has many specific words which indicate how far away the location is and whether it is lower, on the same level, higher, or on the other side of the river. Rather, it has the different function of identifying the clause as a locative one in relationship to the following clause. 


\section{Parallelism created by using speech orienters}

Some instances of parallelism in Ipili chanted tales occur quite naturally as a result of the use of the same speech orienter at the end of a series of lines. In text 17 the words "she said" are referred to as a "speech orienter," using one of the terms from a set of terms developed by Beekman, Callow, and Kopesec (1981) to label various kinds of semantic relationships at the discourse level. Using that same set of terms, what she said in this example is labelled as the "content." The terms "orienter" and "content" constitute a pair of terms that normally occur together because it is quite natural to state what a person said along with a verb which indicates that something was said.

This is consistent with what Rumsey (2005:41-42; citing Jakobson 1970) says that, "All narrative uses of language presuppose at least two distinct events: a speech event in which the act of language use is taking place, and another event which is being narrated." The term "speech orienter" refers to the speech event, and the term "orienter" refers to at least part of the event which is being narrated. In text 17 , the same speech orienter occurs at the end all four lines.

\section{Text 17. Example from "Kau nala tapeyo."}

1154. Ole andipa pele oko naleyo lea.

1155. Ole anati atape lea.

1156. Ole luma yia peyape lea.

1157. Tukunina andaka epope ote lea.
"I am not including the day that you are going now," she said.

"Stay tomorrow," she said.

"Kill the pig the day after tomorrow," she said.

"Come home on the fourth day," she said.

There would be no parallelism between these four lines if the word lea had not been added at the end of each line. Repeating this speech orienter at the end of each sentence of quoted material creates a frame for the contrasting content of what she said in each line. The speech orienter at the end of lines 1155 and 1156 would probably be omitted if someone was just telling another person what instructions someone else had given in a daily situation, but this speech orienter is repeated in each line in this example for an Ipili chanted tale to create more parallelism.

The speech orienter that is used most frequently in Ipili chanted tales is lea, but the speech orienter lapia is sometimes used in two or more successive lines, especially near the beginning of a tale, as in text 18 . The main difference in meaning is that lea refers to an event that happened long ago, while lapia refers to an event that happened more recently. Lapia literally means 'he said', but in this example, no character in the chanted tale is being quoted. Rather, it sounds as though the chanter himself is indicating that he is quoting someone else when he chants the tale. 
The question is, who might he be quoting? This is the same question that I have already discussed above in relation to text 10 . However, the chanter in text 18 has not used the third person singular remote past verb form lea, like the chanter of the tale excerpted in text 10 did. The latter performer used lea more than eighty lines into the tale, so he is not referring to some other chanter who may have told this tale in the indefinite remote past.

The chanter in text 18 has also not used the first person singular imperfect verb form lalo, as the chanter of the tale called "Kau nala tapeyo" did at the beginning of his tale. The chanter of the tale called "Kau tali tapeyo," from which text 18 is taken, has used the third person singular perfect verb form lapia at the beginning of his tale instead. Therefore, this chanter seems to be disassociating himself from the process of telling the tale by using the third person instead of the first person.

Ingemann (pers. comm. 2008) notes that the introductory lines quoted in this example were spoken by the performer rather than chanted, so it does seem that he was focusing on the source of the tale at this point. Given the tense and aspect of the verb that this chanter has chosen, he doesn't seem to be focusing on the telling of the tale as an ongoing process, but rather on the completion of each line of the tale as he begins to tell it. For that reason, in this instance, it seems that this chanter may have thought of the tale itself as an active force making itself manifest to the audience through the performer as each successive line was completed.

However, in two of the other chanted tale performances which I used as sources for examples of parallelism, the chanter chose to use the third person singular remote past verb form lea in the same position at the beginning of his chanted tale. For that reason, in this instance, it would seem more likely that he was giving credit to another chanter who was the source of the tale that he was now chanting. It seems that each Ipili chanter of tales has the freedom to take the credit for a chanted tale himself, to give credit to another chanter, or even to tell it as though the tale itself is an active force in the telling of the tale.

\section{Text 18. Example from "Kau tali tapeyo."}

1. Iwana tepo akali atalaini lapia.

2. Tepo akali atalaini oko ato yalaini lapia.

3. Yia tepone lapia.

4. Yia tepone, iwana lapo atalapele lapia.
"Three unmarried young men exist," he said.

"The three men that exist keep on living," he said.

"A pig is the third one," he said.

"A pig is the third, two young men exist," he said.

In text 18 , lines 1 and 2 would have already been somewhat parallel without adding lapia, because of the repetition of tepo akali in the medial position and the repetition of the verbal suffix -alaini in the final position. The presence of 
iwana in the initial position in line 1 contrasts with its absence in line 2 , and the presence of oko ato in line 2 would contrast with its absence in line 1 . This could be thought of as being two pairs of parallel terms. However, lines 3 and 4 would not be parallel with lines 1 and 2 in any way if the speech orienter lapia had not been added to make them parallel. At this higher level, lapia functions as the repetitive frame for all of the rest of the words in those four lines which serve as contrasting groups of parallel terms.

Two or more lines which would not be parallel in any way by themselves are sometimes made at least somewhat parallel by adding the more complex speech orienter lo atalu ya at the end of each of the lines. The word lo is the medial form of the same Ipili speech orienter mentioned above. The two lines in text 19 differ greatly in terms of length and content, but adding the words lo atalu ya at the end of both of them creates the impression that they are at least somewhat parallel by functioning as a frame for the rest of the words in each line which serve as contrasting groups of parallel terms.

\section{Text 19. Example from "Kau nala tapeyo."}

1277. Iwana epene-ao, lo atalu ya.

1278. Nimbana palu tambu imane palini pia tupa pitaka pupia lo atalu ya.
“Oh good unmarried young man," she was saying.

"Your relatives and in-laws have all gone," she was saying.

Notice that line 1277 would not be a complete sentence by itself if the words lo atalu ya did not occur at the end of that line. The speaker is simply calling the attention of the young man to what she is about to say in line 1278 which ends with the same words as line 1277 . It would be overly redundant to have a complex speech orienter like that at the end of both lines in normal speech. It could be omitted at the end of the first line without any loss of meaning, but using it on both lines creates parallelism.

Another way that chanters create parallelism where it would not naturally occur is by adding the words lama epea at the end of more than one line. Lama is also a form of the verb 'say'. It is normally used to indicate that an action is an ongoing process over a period of time, but chanters of tales seem to use it primarily to create parallelism. The material in each line that precedes lama epea is frequently not a complete sentence. It may be no more than a phrase, a clause, or one or two words that are used to describe someone or something, like the description of the old woman given in lines 1354 though line 1356 in text 20. 


\section{Text 20. Example from "Kau nala tapeyo."}

1353. Okonena anduane wanda mini-yene, "The owner of that (pig) was an old woman," she lama epea. came saying.

1354. Kama-mane latako-pene, lama epea. "Covered with grey hair," she came saying.

1355. Lene pata-pene, lama epea-o.

1356. Wenene pata-pene, lama epea-o.

"Flat round eyes," she came saying-o.

"Flat forehead," she came saying-o.

The words lama epea literally mean 'she came saying', but there are many contexts like this one in which it doesn't make any sense to understand these words as literally meaning that anyone came saying anything. Therefore, it seems that these words are used primarily as a poetic device to enhance the parallelism of two or more phrase or clauses that might not be parallel without them. These two words are used primarily when stringing those phrases and clauses together would make a line too long.

Sometimes the words preceding lama epea form a complete clause including a verb. However, if the words lama epea had been omitted from lines 524 and 525 in text 21, neither of the clauses would have been a complete sentence by itself because they both end with medial verb forms. Therefore, another clause that ends with a final verb form had to be added to produce a complete sentence according to the rules of Ipili grammatical structure. Lines 1353 and 1354 in text 20 do not have the added syllable -o like lines 1355 and lines 1356, so it seems that the chanter preferred to have two pairs of parallel lines instead of having them all parallel.

In text 21, the word epea at the end of lines 524 and 525 has a final verb form, so both seem to be complete sentences, but having the words "she came saying" at the end of both lines does not sound very natural. However, if those words at the end of line 524 and 525 are disregarded, the remaining clauses chain together to form a fairly natural sentence in both Ipili and English. In examples like this, it seems that lama epea has been added at the end of each clause in a long complex sentence in order to break it up into shorter pieces that can each easily be spoke as one line.

\section{Text 21. Example from "Kau nala tapeyo."}

524. Oo andaipa okone amonga poto, lama epea.

525. Atu ambingane pekayu loto, lama epea.

526. Ambingane muli-mane kala lamialu, Having hit (the pig) with a club, let it fall down. tepa ya.

Lines 524 and 525 would already be parallel without adding lama epea because the medial verb ending -to is the same in both lines and would have served as a very limited frame for the rest of the words in those two lines which function as

"That one we saw here going over there," she came saying.

"Arriving over there," she came saying. 
groups of parallel terms; adding the words lama epea creates a larger repetitive frame for those contrasting terms. Sometimes the words lama epea are augmented by adding the syllable -ne. Adding that syllable to the verb epea in normal Ipili might indicate that the person who is speaking actually witnessed the event being mentioned, but it does not seem to change the meaning in that way in all cases in a chanted tale.

\section{Parallelism created by using sense orienters}

Some verbs function as orienters that indicate which one of the five senses people have used to gain information about their environment. The rest of the clause or sentence states what information is being gained. The three lines in text 22 all end with the Ipili words ale ya, which mean 'he heard'.

\section{Text 22. Example from "Kau tali tapeyo."}

251. Kuaka puli toko pulu yanga ale ya. He heard laughing like the cutting of a puli tree

252. Wana tupa kuaka waiyawe toko pulu He heard the girls laughing like the cutting of a yanga ale ya. waiyawe tree.

253. Wana tupa kuaka puli toko pulu He heard the girls laughing like the cutting of a yanga ale ya. puli tree.

Text 23 is another illustration of using a sense orienter to create parallelism, since the ability to see is another one of our senses. A chanter sometimes uses either the singular or plural interrogative form of the verb "see" to ask the listeners if they envision what he is telling them. He may ask whether they envision not only characters and other physical objects, but also events in the chanted tale as illustrated by text 23 .

In the following example, the use of the Ipili first person plural interrogative verb form andeyaipe at the end of each of the six lines illustrates the use of the same verb form at the end of more than one line to enhance the parallelism between lines. Lines 9 and 10 would obviously be parallel already without the word andeyaipe because the words amene kayane in the initial position and the words mialane yalua in the final position would function as the frame, and the words aya sia in the medial position in line 9 and the word ipa in line 10 would serve as contrasting parallel terms.

In the same way, lines 12 and 13 would already be parallel without the word andeyaipe because the word aya in a medial position and the words yale yalua in the final position would function as the repetitive frame. The contrastive words kene and kini in the initial position would serve as parallel terms along with the contrastive pairs of terms kengali kapu in line 12 and apa peya-peya in line 13 in another medial position. 


\section{Text 23. Example from "Kau nala tapeyo."}
9. Amene kayane ana sia mialane yalua Do you see that the little youngest brother andeyaipe. customarily gets firewood?
10. Amene kayane ipa mialane yalua andeyaipe.
11. Aya Kau Nala Tape yalua andeyaipe.
12. Kene ana kengali kapu yale yalua andeyaipe.
13. Kini aya, ana peya-peya yale yalua andeyaipe.
14. Kawane itini yaiyapia yoko mina pelene yale yalua andeyaipe.
Do you see that the little youngest brother customarily gets water?
Do you see little Kau Nala Tape?
Do you see (his) little legs like dry Piper trees?
Do you see (his) little arms like peya-peya trees?
Do you see (his) hair like yaiyapia tree leaves which have been held and hit?

It would be quite unusual to have such a long series of questions in any other genre or type of discourse in the Ipili language, so this long series of questions can be considered a creative poetic feature intended to encourage the listeners to envision what he is describing to them. Text 23 occurs near the beginning of a performance, whereas text 24 occurs much later in another performance.

Text 24 and the next four are consistent with Rumsey's report that many $\mathrm{Ku}$ Waru people have pointed out that all performers of chanted tales seek to keep the attention of their listeners focused on the story and by presenting it in a way that "makes them see and hear it happening in their own minds as the performer does in his or hers" (Rumsey 2001:215).

\section{Text 24. Example from "Kau nala akali."}

240. Epo peapele oko iyunga ote tupa yalua andelepa.

241. Kesa minaka kesa minaka epo peane oko yalua andelepa.
Do you see that the two went back and forth up there?

Do you see that the one went back and forth trying to grab it?

The chanter in text 24 uses the second person singular interrogative form of the verb "see," even though it is almost certain that many people were listening to his tale. This is an example of addressing his listeners as individuals, which may further enhance their sense of personal involvement. In both texts 24 and 26, the chanter asks the listeners if they can envision what the chanter is describing.

Lines 240 and 241 would be parallel already without the word andelepa because yalua would function as a frame for the rest of the words in each line which would therefore serve as groups of parallel terms; adding the word andelepa to the repetitive frame makes the parallelism more obvious because it then consists of two words instead of just one.

Text 25 is another illustration of the use of an Ipili first person dual verb form to reinforce the connection between himself as the chanter of the tale and each 
one of his listeners as individuals. He is telling each listener to join him in envisioning what he himself is seeing in his own mind. The words itai eka in the initial position and longone taka mindi epeya andeyapa in the final position provide a very big repetitive frame within which the contrasting terms lewa in line 1815 and puluma in line 1816 serve as parallel terms to create a high degree of parallelism.

\section{Text 25. Example from "Kau tali tapeyo."}

1815. Itai eka lewa longone taka mindi epeya andeyapa.

1816. Itai eka puluma longone taka mindi epeya andeyapa.
We two are seeing that many lewa doves are coming together.

We two are seeing that many puluma doves are coming together.

Sometimes a chanter uses the past tense of the verb "see" to ask whether the listener "saw" what he has already mentioned in previous lines of the chanted tale. In text 26 , the chanter uses the first person singular verb form lauwa, which literally means 'which I said', to establish a link between his telling of the story and the listener's visualization of what he is referring back to at this point.

The chanter also uses the singular form of the verb in his question, even though it is likely that many people were listening to his tale. There would be minimal parallelism between lines 24 and 25 in this example without the words lauwa andapipa, but adding those two words at the end of these two lines enhances the parallelism.

\section{Text 26. Example from "Kau nala akali."}

24. Yia piango-la lapo lauwa andapipa. Did you see the dog and the pig I mentioned?

25. Iwanaya lapo lauwa andapipa.

Did you see the two boys I mentioned?

In text 27 , the first person dual perfect verb form andaipa literally means 'which you and I have seen'. Chanters use it to refer back to a character or other information that has previously been mentioned. The first person dual form of the verb in this context stresses the connection between himself as the story teller and each of his listeners as individuals. The use of lauwa andaipa at the end of two or more lines in succession enhances parallelism.

Even without the words lauwa andaipa, the words yale mindi in lines 179 and 180 would function as a repetitive frame for the rest of the words in those two lines which serve as groups of parallel terms. However, the use of the words lauwa andaipa at the end of all three of the descriptive lines makes them all more parallel, even though line 181 is slightly different because it has the additional syllable - $o$. Adding the words lauwa andaipa once again encourages the listeners to envision the main character or the action in which he is involved. 


\section{Text 27. Example from "Kau nalane akali."}

179. Kawane itini yaiyapia yoko yapiane yale mindi lauwa andaipa,

180. inga munini panjea komani yale mindi lauwa andaipa,

181. kau one neenga atene mindi lauwa andaipa-o,

182. oo andaipa okomane lakea ekapu jaa lo leangato, yalua andalaini.
The one I mentioned who we two saw who looked like he had yaiyapia tree leaves for hair, the one I mentioned who we two saw whose nose was like dry bamboo,

the one I mentioned who we two saw with light skinned lizard skin on his teeth-o,

they customarily see that one who we two saw here (walking with his) cordyline leaves flapping.

There is a sense in which an Ipili tindi could be compared with television, since the chanter tells a story and then repeatedly asks his hearers to envision the characters and events in the story. ${ }^{6}$ We could say he "tells-a-vision" and uses the verb "see" in its various forms to encourage the listeners to visualize what he is saying.

\section{Parallelism created or enhanced by using other sentence-final verbs}

Many other verbs occur at the end of two or more successive lines in Ipili chanted tales. The verb ya is used when referring to objects or creatures like snakes that are often in a horizontal position. This verb means 'was' or 'were' in the past tense. In text 28, even without the word $y a$ at the end, lines 183 and 184 would be parallel because the word ima in a medial position and the words eyaka palene in the final position would function as a repetitive frame. The words napi kene in line 183 and kini in line 184 in another medial position would serve as parallel terms along with nimapu in line 183 and momapu in line 184 as a second pair of parallel terms. Adding $y a$ at the end of both lines enhances the repetitive frame by making it bigger.

\section{Text 28. Example from "Kau nala tapeyo."}

183. Napi kene ima nimapu eyaka palene Down below (his) legs were (like they) had ya. nimapu vines inside of them.

184. Kini ima momapu eyaka palene ya. (His) arms were (like they) had momapu vines inside of them.

In text 29, even without the final word yane, the two lines are already highly parallel, since pati mialu in the initial position and nuu mindi yane in the final position create a large repetitive frame for the contrasting parallel terms upe in line 651 and lombami in line 652, which refer to different kinds of netbags. The verb in the final position is formed by adding the suffix -ne to the end of the verb ya.

6 Note the comparison that is made by Yuna man Kenny Kendoli (chapter 2) between the experience of listening to pikono chanted tales and watching exciting action films. 
Sung Tales from the Papua New Guinea Highlands

\section{Text 29. Example from "Kau nala tapeyo."}

651. Pati mialu, ambi upe nuu mindi yane.

652. Pati mialu, ambi lombami nuu mindi yane.
Having taken (the food) out of the ground oven, there was an upe net bag nearby.

Having taken (the food) out of the ground oven, there was a lombami net bag nearby.

The suffix -ne which occurs at the end of the verb in text 29 can also be added to most other verbs. In text 30 , it has been added to atea, which is the remote past form of the Ipili verb which is used with masculine subjects, subjects like trees that stand upright, and many other subjects including dogs. It means 'was' when it is in the past tense.

\section{Text 30. Example from "Kau nala akali."}

790. Piangone Waleya atu ateane.

791. Iwanaya piako atu ateane.
The dog Waleya was along. That young boy was along.

\section{Conclusion}

This chapter has explored parallelism and poetics in sung narratives among Ipili speakers in the Papua New Guinea Highlands. Using examples from several chanted tales based on the same general theme, the chapter illustrates four principal means by which narrators use parallelism in Ipili tales. Parallelism follows the binary principal whereby meaning comes from both repetition and contrast. There is systematic repetition between lines, but with variation due to the inclusion of contrasting elements.

Four types of parallelism have been discussed and exemplified. Firstly, parallelism may involve substituting terms within an unchanging frame, such as referring to the same mountain, tree, or animal by different names in successive lines. Thus words change though the meaning remains the same. English speakers are familiar with poetic parallelism between lines of poetry and songs in which the last words of two lines rhyme. Ipili speakers recognise such linguistic practices also, as seen in the second type parallelism, in which the aesthetic appeal of the tale is enhanced by the use of line-final verbs that rhyme or similar non-semantic syllables. A third form of parallelism involves the repetition of a medial verb form or a suffix linked to a medial verb over several lines functioning as a frame, with all of the preceding words in each line functioning as groups of parallel terms. The fourth type of parallelism makes use of a frame which is formed through the repetition of the same sentence-final verb form at the end of two or more lines. Each of these four means of creating parallelism involves the 
interaction of contrasting parallel terms or syllables within a repeated frame in a systematic and creative way, so as to produce a performance that adults as well as children listen to with rapt attention.

In ordinary speech, where the focus is on providing information, people will speak concisely, listing different items in a single clause. However, the narrators of Ipili sung narratives place different terms in separate lines, leading to the parallelism and poetics of the genre of tindi. At times the meanings may change to provide semantic parallelism, while at other times there may be lexical parallelism that makes no difference to the meaning. The purpose of such creative parallelism is to produce a narrative with aesthetic appeal that will draw the listeners into the tale.

This chapter helps to show the complexity and poetic creativity found in Ipili tindi. However, it is difficult to capture the dynamism of tindi performances in a textual analysis such as this. The narrator appeals to the listeners' senses, calling on them to hear or envision the characters or events referred to. This may involve a series of questions addressed to the listeners to involve them so that they become participants in the tale. In this way, the chanted narrative takes on an active force manifest in the hearers through the performer.

Performances of tindi are an important part of Ipili tradition. However, the Ipili context is changing rapidly, particularly with the influx of outsiders due to the presence of the Porgera gold mine. English is the official language for young people taking part in formal education. In market places in Porgera, one may hear as much Enga and Tok Pisin spoken as Ipili. Modern music and television are the most common forms of evening entertainment. Yet the poetics of tindi discussed in this chapter still fascinate Ipili speakers young and old on rare occasions when tindi are heard live or even over the radio. The older generation who grew up with the tradition are passing away and prospects for live performances of the tradition of chanted narratives will depend on the degree to which future generations of Ipili speakers can maintain the linguistic skills and poetic imagination to create tindi.

\section{References}

Beekman, John, John Callow, and Michael Kopesec. 1981. The Semantic Structure of Written Communication. Dallas: Summer Institute of Linguistics.

Fox, James J. 1977. "Roman Jakobson and the Comparative Study of Parallelism." In Roman Jakobson: Echoes of His Scholarship, edited by Cornelis H. van Schooneveld and Daniel Armstrong, 59-90. Lisse: Peter de Ridder Press.

Gibbs, Philip. 1978. “Kaunala Tape: Towards a Theological Reflection on a New Guinea Initiation Myth." MA thesis, Catholic Theological Union (Chicago). 
Golub, Alex. 2001. Gold Positive: A Short History of Porgera 1930-1997. Mt. Hagen: Porgera Development Authority.

Hopkins, Gerard. 1959. Poetic Diction: The Journal of Papers of Gerard Manley Hopkins. Edited by Humphrey House; completed by Graham Storey. London: Oxford University Press.

Hunter, Alistair G. 1999. Psalms. London: Routledge.

Ingemann, Frances. 1964. Unpublished transcription of a chanted tale told by Yandapake.

. 1968. "The Linguistic Structure of an Ipili-Paiyala Song Type." In Proceedings: 8th International Congress of Anthropological and Ethnological Sciences, Tokyo and Kyoto, Vol. 2: Ethnology, 398-400. Tokyo: Science Council of Japan.

Jackson, Richard, and Glenn Banks. 2002. In Search of the Serpent's Skin: The Story of the Porgera Gold Project. Port Moresby: Placer Niugini Ltd.

Jakobson, Roman. 1966. "Grammatical Parallelism and Its Russian Facet." Language 42 (2): 398-429.

. 1970. "Shifters, Linguistic Categories, and the Russian Verb." In Selected Writings, Vol. 2: Word and Language, 130-47. The Hague: Mouton.

Kale. 1974. "Kau nala tapeyo." Text of transcribed tindi recorded in 1974 and included in Gibbs 1978.

Kaneanda. 1965. "Kau tali tapeyo." Unpublished manuscript provided by Frances Ingemann.

Lowth, Robert. 1834. Isaiah: A New Translation with a Preliminary Dissertation and Notes, Critical, Philological, and Explanatory. Boston. (Orig. pub. in 1778.)

Pawley, Andrew. 2005. "The Chequered Career of the Trans New Guinea Hypothesis: Recent Research and Its Implications." In Papuan Pasts: Cultural, Linguistic and Biological Histories of Papuan-Speaking Peoples, ed. Andrew Pawley, Robert Attenborough, Jack Golson, and Robin Hide, 67-107. Pacific Linguistics, 572. Canberra: Australian National University.

Ross, Malcolm. 2005. "Pronouns as a Preliminary Diagnostic for Grouping Papuan Languages." In Papuan Pasts: Cultural, Linguistic and Biological Histories of Papuan-Speaking Peoples, ed. Andrew Pawley, Robert Attenborough, Jack Golson, and Robin Hide, 15-65. Pacific Linguistics, 572. Canberra: Australian National University. 
Rumsey, Alan. 2001. "Tom Yaya Kange: A Metrical Narrative Genre from the New Guinea Highlands." Journal of Linguistic Anthropology 11 (2): 193239 .

2005. "Chanted Tales in the New Guinea Highlands of Today: A Comparative Study. In Expressive Genres and Historical Change: Indonesia, Papua New Guinea, and Taiwan, edited by Pamela J. Stewart and Andrew Strathern, 41-81. Anthropology and Cultural History in Asia and the IndoPacific. Hants: Ashgate Publishing.

Yandapake. 1964a. "Kau nala akali." Unpublished manuscript provided by Frances Ingemann.

. 1964b. "Kau nalane akali." Unpublished manuscript provided by Frances Ingemann. 